\title{
Challenges to Parental Involvement in Children's Education at a Primary School: A Rasch Analysis
}

\author{
Kamal J. I. Badrasawi \\ Kulliyyah of Education, \\ International Islamic University Malaysia \\ Kuala Lumpur \\ kamalbadrasawi@iium.edu.my
}

\author{
Humaer Yahefu \\ Kulliyyah of Education, \\ International Islamic University Malaysia \\ Kuala Lumpur \\ humargul.yaqup@gmail.com
}

\author{
Madihah Khalid \\ Kulliyyah of Education, \\ International Islamic University Malaysia \\ Kuala Lumpur \\ madihahkhalid@iium.edu.my
}

\begin{abstract}
Literature has evidenced the positive significant role of parental involvement in children's personality development and education. However, research on parental involvement in children's education is sparse in rural areas, especially among ethnic minorities in China. Hence, a research project was conducted to examine the level of parental involvement and its role in influencing children's academic achievement in these areas; and to identify the challenges to parental involvement. This paper aimed to identify the challenges to parental involvement using the cross-sectional survey design. The parents' of Grades Three and Four school children were selected to answer a questionnaire on parental involvement. The items on challenges to parental involvement were analyzed using the Rasch Measurement Model (Winsteps software program, version 4.1.0). The Rasch analyses revealed that the research instrument met the measurement requirements. Parents' low proficiency in the Chinese language and the complexity of the school subjects were the biggest challenges to parental involvement. This research has provided useful information to parents, teachers, school administration and policy makers. Further research could be conducted using more items and larger samples from other school grades. Qualitative research is recommended to obtain more in-depth information on parental involvement in general, and the challenges in particular.
\end{abstract}

Keywords: Parental involvement, Rasch measurement model, challenges to parental involvement, children's personality development, China's ethnic minorities

\section{INTRODUCTION}

Literature has reported the positive significant relationship between parental involvement and children's personality development and education (Chen, 2005; Joyce Levy Epstein \& Karweit, 2014; Catsambis, 2001; Fan \& Chen, 2001; Galindo \& Sheldon, 2012; Jeynes, 2005a; Mo, 2008; Sheldon \& Epstein, 2005; Smalls, 2010; Smith, 2011). The positive role of parental involvement in enhancing students' academic achievement in early childhood to adolescence is also documented (Fan \& Chen, 2001; Gao, 2006; Henderson \& Mapp, 2002; Hong \& Ho, 2005; Mo, 2008; Smalls, 2010; Tam \& Chan, 2009; Wang, 2015). To achieve success in children's education, there should be a comprehensive cooperation among schools, communities and parents. Christenson and Sheridan (2001) recognized the necessity of cooperation between 
parents and schools in order to complete their common goals to maximize children's success in education.

However, literature has identified barriers and challenges that limit parents' involvement in their children's education. These challenges refer to the difficulties that hinder parents from being effectively involved in their children's education at home and at school. Antoine (2012) and Graham-Clay (2005) defined challenges to parental involvement in the aspects of physical, cultural, social, emotional, or psychological issues in the involvement. For the purpose of this study, challenges to parental involvement might be parent-related challenges, such as parents' educational level, time, socioeconomic status, and language skills (Hill \& Taylor, 2004; Hong \& Ho, 2005; Smith, 2011; Somers, Owens, \& Piliawsky, 2009; Trotman, 2001). They might also be school-related challenges, such as overloaded homework, meetings and volunteer opportunities for parents (Patrikakou, 2008); or child-related challenges, such as children may not want their parents to be involved in their study.

For instance, Smith (2011) found communication and language to be among the barriers to parental involvement. Parents' educational level is significantly associated with students' academic achievement because parents with higher educational level can contribute to children's education by being more involved in their school work at home (Hong \& Ho, 2005; Wang, 2015). Parents may also not be able to provide learning opportunities at home because of their low socioeconomic status. This idea is stated in Hill and Taylor (2004) and Trotman (2001) who showed that family's low socioeconomic status, parents' busy schedule and low educational level resulted in low parental involvement. In addition, parents' time and life demands can be barriers to them in participating in school activities or helping children in their school work at home. Parents often reported they could not get involved in school because school activities were conducted during inconvenient times, or the parents needed more time to help around the house (Patrikakou, 2008).

It is important to mention that research has been conducted to find out the best strategies to meet the challenges to parental involvement (Antoine, 2012; Bronfenbrenner, 1979; Green, Walker, Hoover-Dempsey, \& Sandler, 2007; Smith, 2011; Trotman, 2001). For example, establishing an effective partnership between school and family would have a great impact on parental involvement and students' academic achievement (Antoine, 2012; Bronfenbrenner, 1979; Christenson \& Sheridan, 2001; Epstein et al., 2002; Epstein \& Sheldon, 2006; GrahamClay, 2005).

In specific rural areas with ethnic minorities in China, research on parental involvement is still sparse; thus, a study was conducted to examine the levels of parental involvement and investigate its role in primary school children's academic achievement. The objective of this paper is to examine and identify the challenges to parental involvement.

\section{METHODOLOGY}

\section{Research Design and Respondents}

The cross-sectional survey design, which is commonly used in education, was utilized (Creswell, 2013; Gay, Mills, \& Airasian, 2011). Two hundred (200) parents of Grades Three and Four school children were selected from a primary school in the 2015/2016 academic year in a rural area with ethnic minorities in China to answer the survey. The respondents were $54.6 \%$ mothers $(n=107)$ and $44.9 \%$ fathers $(n=88)$ with mean age 41 years. A large majority of them were farmers $(90.4 \% ; n=179)$, indicating the sample's low socioeconomic status. 
About $76.5 \%(\mathrm{n}=153)$ had basic and intermediate levels in Chinese language; $28.5 \%(\mathrm{n}=57)$ had a primary school education, $27 \%(\mathrm{n}=54)$ secondary school, $31.5 \%(\mathrm{n}=63)$ high school, and only $13 \%(\mathrm{n}=26)$ had a diploma or bachelor's degree qualification.

\section{Instrument}

A 39-item questionnaire on parental involvement was used. The nine (9) items on challenges to parental involvement $(\mathrm{CH})$ were used for the purpose of the current study. These items include parent-related factors such as parents' level of educational background, time and levels of Chinese language skills. Also included are school-related factors in terms of providing helpful information to parents, offering volunteer opportunities for parents at school, and scheduling activities at convenient times. Child-related factors such as children's acceptance of their parents' involvement in their education were also included. The responses to these items were rated using a 5-point Likert scale: (1) Strongly Disagree, (2) Disagree, (3) Neutral, (4) Agree and (5) Strongly Agree. In addition, one open-ended question on the challenges to parental involvement was added at the end of the survey to give the respondents the opportunity to add any other challenges to their involvement in their children's education. It is important to note that the survey was translated from English into Chinese by one of the researchers, and checked by a bilingual teacher. Cheng and Dörnyei (2007) believe that if the questionnaire is presented in the respondents' own mother tongue, the quality of the obtained data improves.

Five education experts from a Malaysian public university examined the content validity of the entire research instrument. They deleted unrelated items; made a few changes to other items, and recommended a few more to be added to the scale.

\section{Data Analysis}

The one-parameter Rasch modeling for polytomous data was used to examine the psychometric properties of the instrument, and the challenges to parental involvement, i.e. to identify the order of the challenges as endorsed by the respondents (parents). Winsteps version 4.1.0 was used to conduct the Rasch analysis of the polytomous data (Linacre, 2018). The Rasch Measurement Model was used because it possesses characteristics that meet the requirements of fundamental measurements, and provides necessary diagnostic information about the whole scale and individual items and persons (Boman \& Curtis, 2007; Bond \& Fox, 2015; Wright \& Stone, 1979). It also helps make a comparison of item difficulty and person ability on one single interval scale (Bond \& Fox, 2015). Persons are placed at a relevant position on one side of the scale and item difficulties on the other side. The most difficult items to be endorsed are placed at the top of the scale, while the easiest to be endorsed, at the bottom of the scale (Bond \& Fox, 2015; Wright \& Stone, 1979).

\section{RESULTS}

The Rasch analyses, using Wisnsteps version 4.0.1 (Linacre, 2018), revealed that the research instrument met the measurement requirements, except more items were needed at the upper and lower ends of the scale for better targeting. For the purpose of the study, the item and person reliability indices, unidimensionality through three indicators (Item polarity, Item Fit, and PCA residuals), and category functions were examined (Bond \& Fox, 2015; Linacre, 2018). 
Difficulty measures and item-map were used to figure out more clearly which items were difficult or easy to be endorsed by the parents of school children. The most difficult items to be endorsed were placed towards the top of the scale and the easiest to be endorsed towards the lowest part.

Having deleted six (6) of the highest misfit persons, Table 1 shows that the reliability of item difficulty measures was very high (0.98), implying that the item difficulty ordering is highly replicable with other similar samples. The item separation index was $>2$. The person reliability was quite high at 0.80 , indicating that it is highly likely that person ability ordering could be replicated with items of the same difficulty. The person separation index was $>2$. (Bond \& Fox, 2015; Linacre, 2018). Table 1 also shows item polarity (i.e. point-measure correlation coefficients) which indicates if the items are in the same direction to define the measured construct. Relatively high positive values are required (Bond \& Fox, 2015; Linacre, 2018). All the point measure correlation (PTMEA CORR.) coefficients for the nine (9) items are positive. Moreover, fit statistics were used to ensure that the items were contributing meaningfully to the measurement of the variable or construct as expected by the model (Bond $\&$ Fox, 2015). The infit and outfit mean-square statistics are the concern. The items within the recommended ranges are considered meaningful to the measurement; whereas the values below the ranges are considered as overfitting, and those above the ranges are considered as misfitting. For this study's purpose, the range 0.5-1.5 was used (Bond \& Fox, 2015). Table 1 shows that the infit and outfit mean-squares of individual items are within the specified range $(0.5-1.5)$. Furthermore, the Z-std values for both the infit and outfit statistics are within the range -2 to +2 , except for items 8 and 9 which are not far departed from the recommended range.

Table 1

Item Measures, Fit Statistics and Point-Measure Correlation Coefficients

\begin{tabular}{|c|c|c|c|c|c|c|c|c|}
\hline No. & Item & Measure & S.E & $\begin{array}{l}\text { Infit } \\
\text { MNSQ }\end{array}$ & ZSTD & $\begin{array}{l}\text { Outfit } \\
\text { MNSQ }\end{array}$ & ZSTD & $\begin{array}{l}\text { PT-Measure } \\
\text { CORR }\end{array}$ \\
\hline 5 & $\begin{array}{l}\text { My child doesn't want me to help him/ } \\
\text { her in his/her study. }\end{array}$ & 1.04 & .09 & 1.20 & 1.6 & .1 .08 & .6 & .41 \\
\hline 8 & $\begin{array}{l}\text { My child's school does not schedule } \\
\text { activities and conferences at convenient } \\
\text { times. }\end{array}$ & .59 & .08 & .70 & -3.1 & .66 & -3.2 & .57 \\
\hline 2 & $\begin{array}{l}\text { I do not have enough time to help my } \\
\text { child's school work. }\end{array}$ & .34 & .08 & .95 & -.5 & .96 & -.4 & .55 \\
\hline 7 & $\begin{array}{l}\text { My child's school does not offer parents } \\
\text { volunteer opportunities to get involved } \\
\text { in children's education. }\end{array}$ & .25 & .08 & 1.05 & .6 & 1.08 & .8 & .57 \\
\hline 9 & $\begin{array}{l}\text { Parent teacher association meetings } \\
\text { does not provide useful information for } \\
\text { parents on developing home routines, } \\
\text { conditions and environments that } \\
\text { support and improve children's } \\
\text { learning. }\end{array}$ & -.07 & .08 & 1.13 & 1.4 & 1.11 & 1.1 & .56 \\
\hline 1 & $\begin{array}{l}\text { I do not know how to help my child do } \\
\text { well in school. }\end{array}$ & -.18 & .08 & 1.00 & .0 & 1.04 & .5 & .62 \\
\hline 6 & My child has a lot of homework. & -.19 & .08 & 1.00 & .0 & 1.05 & .5 & .60 \\
\hline 3 & $\begin{array}{l}\text { My Chinese language skills are not up to } \\
\text { the level to help my child in his/her } \\
\text { school work. }\end{array}$ & -.84 & .08 & .91 & -.9 & .96 & -.3 & 67 \\
\hline 4 & $\begin{array}{l}\text { My child's subjects are } \\
\text { complex/difficult for me to explain. }\end{array}$ & -.93 & .08 & .91 & -.9 & .99 & .0 & .66 \\
\hline Means & & .00 & .08 & .98 & -.2 & .99 & -.1 & \\
\hline \multicolumn{9}{|c|}{ Reliability and Separation } \\
\hline & Item Reliability & 0.98 & & & & & & \\
\hline & Item separation & 7.22 & & & & & & \\
\hline & Person Reliability & 0.80 & & & & & & \\
\hline & Person Separation & 2.1 & & & & & & \\
\hline
\end{tabular}


The principal component analysis of residuals is an indicator to ensure that data fit the model, and items are working together to measure a single unidimensional construct. Table 2 shows that unidimensionality is met. The variance explained by the measure is 48.9 , and the largest factor extracted from the residuals is equivalent to 2.098 units which have the strength of about 2 items (Linacre, 2018).

Table 2:

Standardized Residual Variance in Eigenvalue Units (= Item Information Units)

\begin{tabular}{lccc} 
& & Eigenvalue & Observed \\
\hline Total raw variance in observations $=$ & 17.6208 & $100.0 \%$ & $100.0 \%$ \\
Raw variance explained by measures $=$ & 8.6208 & $48.9 \%$ & $47.9 \%$ \\
Raw variance explained by persons $=$ & 2.8520 & $16.2 \%$ & $15.9 \%$ \\
Raw Variance explained by items $=$ & 5.7688 & $32.7 \%$ & $32.1 \%$ \\
Raw unexplained variance (total) $=$ & 9.0000 & $51.1 \%$ & $100.0 \%$ \\
Unexplained variance in 1st contrast $=$ & $\mathbf{2 . 0 9 8 6}$ & $\mathbf{1 1 . 9} 9 \%$ & $23.3 \%$ \\
\hline
\end{tabular}

Table 3 shows that category functions are appropriate. The minimum number of responses per category is $>10$. The average measures increase monotonically $(-1.46<-0.79<-0.08<0.7<$ $0.73)$. The thresholds are also increasing monotonically $(-1.63<-.62<-0.69<1.69)$. The fit statistics for each rating scale are $<2$, implying that there is no noise in the measurement process (Bond \& Fox, 2015). Figure 1 also displays the distances between adjacent categories.

Table 3:

Summary of Category Structure. Model="R"

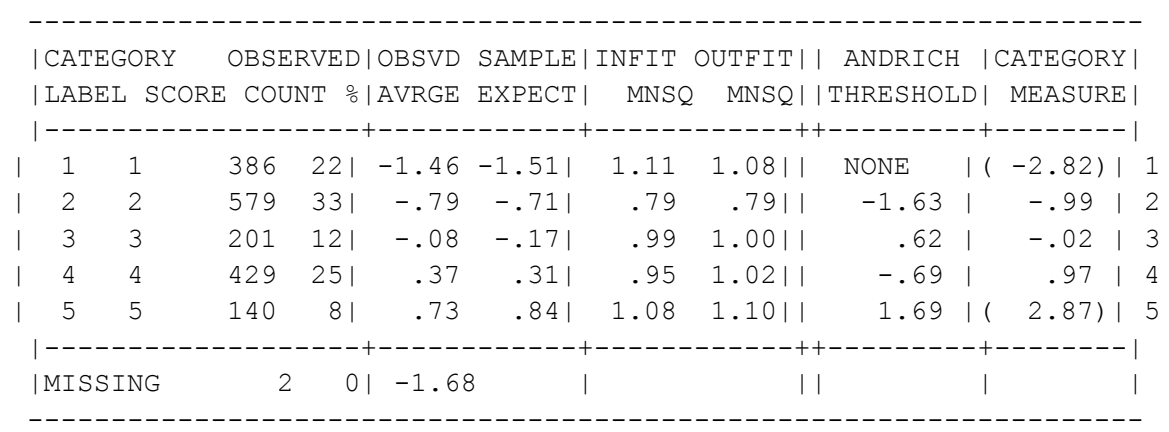

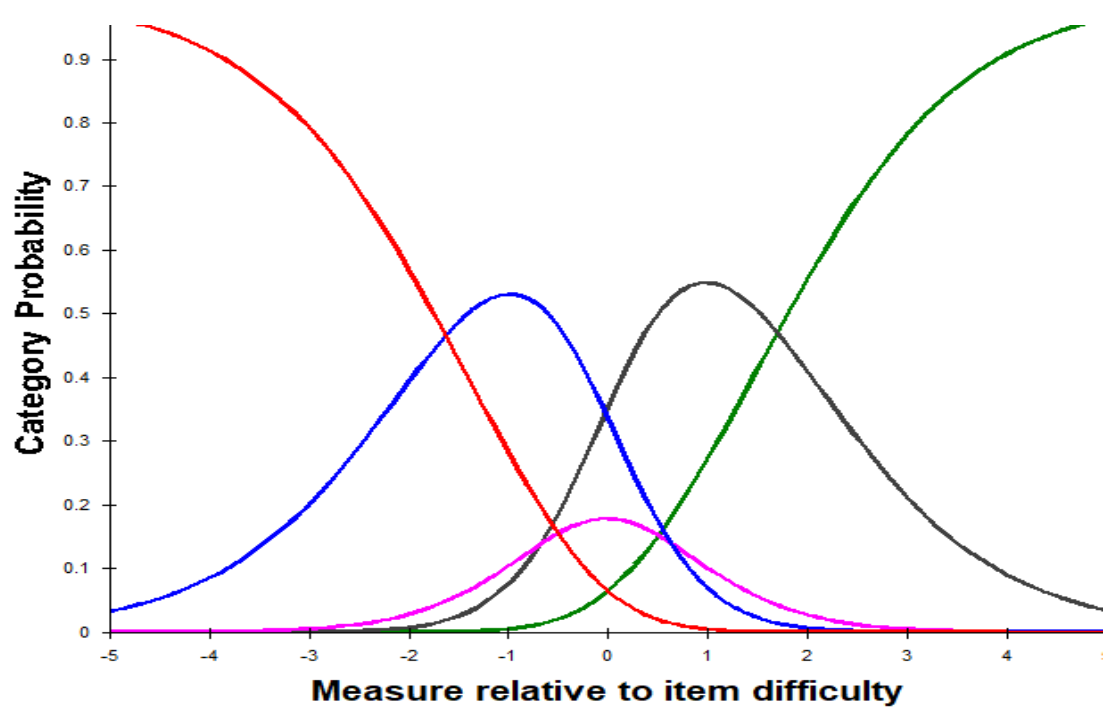

Figure 1: Category Characteristic Curves

This study aimed mainly to find out the challenges to parental involvement in school children's education at a primary school in a rural area with ethnic minorities in China. Overall, it was not easy for the parents to endorse and agree on the items describing the challenges to their 
involvement in their children's education (Figure $2 \&$ Table 1). The mean of parents' ability was (-0.56 logit), lower than the mean of item difficulty (0.0 logit). The Item-Map (Figure 2) clearly displays the distribution/hierarchy of all items on one interval scale. The highly endorsed items are placed towards the lower part, and the least endorsed ones are placed towards the upper end of the scale.

The most difficult items to be endorsed by the parents were items $\mathrm{CH} 5$ (My child doesn't want me to help him/her in his/her study, 1.04 logit); item CH 8 (My child's school does not schedule activities and conferences at convenient times, 0.59 logit); item CH 2 (I do not have enough time to help my child's school work, 0.34 logits); and item $\mathrm{CH} 7$ (My child's school does not offer parents volunteering opportunities to get involved in children's education, 0.25 logits). On the other hand, the easiest items endorsed by the parents were $\mathrm{CH} 4$ (My child's subjects are complex/difficult for me to explain, -.93 logit); $\mathrm{CH} 6$ (My child has a lot of homework, -0.19 logit); CH 1 (I do not know how to help my child do well in school, -0.18 logit); and $\mathrm{CH} 9$ (Parent-teacher association meetings does not provide useful information for parents on developing home routines, conditions and environments that support and improve children's learning, -0.07 logit).

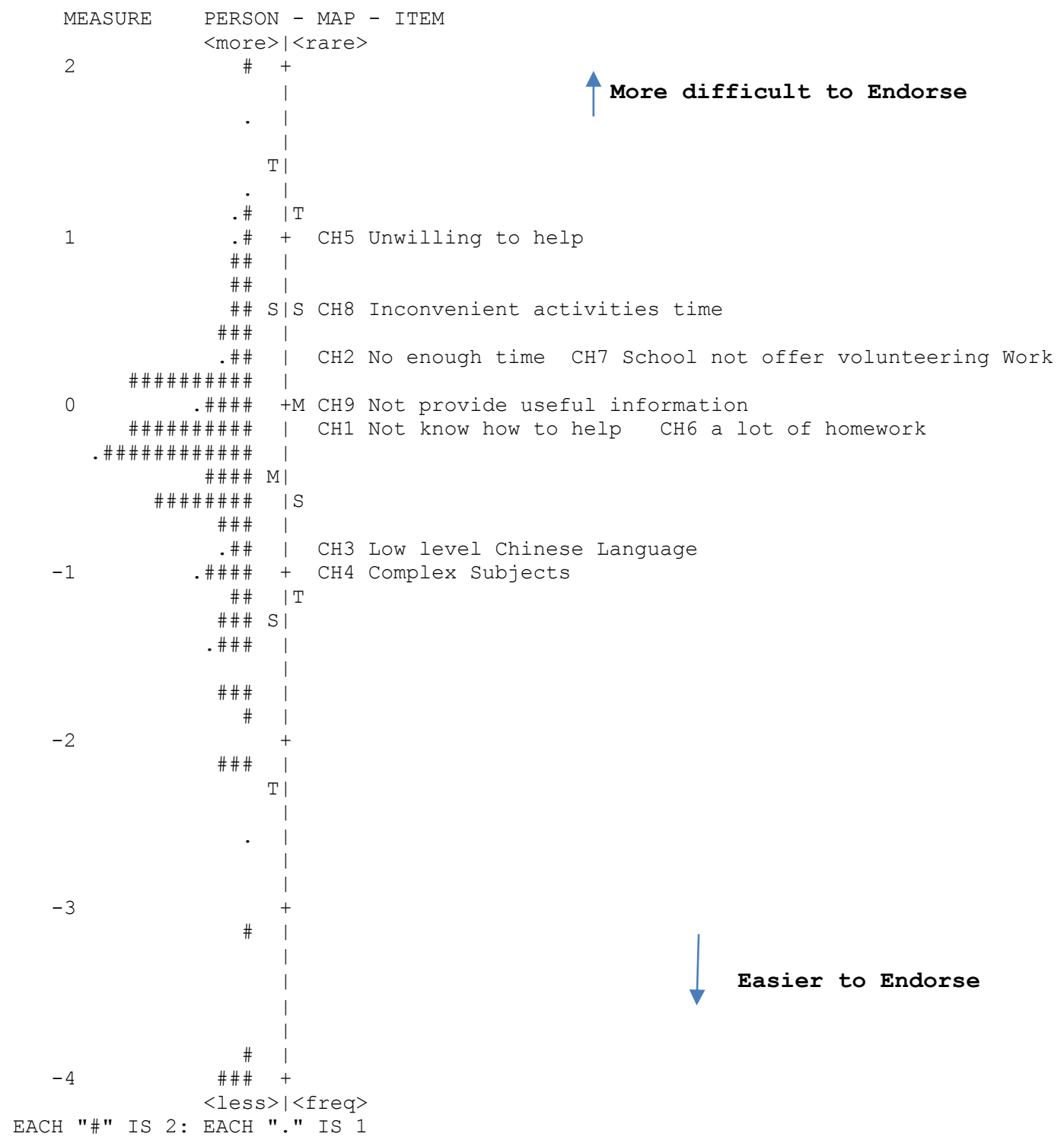




\section{DISCUSSION}

Though the role of parental involvement in school children's personality development and education has been studied in many settings in the world, there is a need to examine the level and role of parental involvement in school children's education as well as identify its challenges at schools in rural areas with the ethnic minority in China. It is observed that in China, most of the research pertaining to parental involvement has been conducted in developed areas; for example, Hong Kong and Shenzhen (Chen, 2010; Gao, 2006; Hong \& Ho, 2005; Lau, Li, \& Rao, 2011; Tam \& Chan, 2009; Wang, 2015). Thus, this study aimed to explicitly identify the challenges to parental involvement in school children's education at a primary school in a rural area in China from the parents' perspectives. Antoine (2012) highlighted the importance of the perceptions of parents and teachers towards barriers/challenges to parental involvement, and its role in children's achievement at school. He found that parents and teachers' perceptions affect students' achievement and behaviors, as well as teacher-parent and home-school communications.

Overall, the findings of this study showed that it was not very easy for the parents to agree upon the statements on challenges to parental involvement in school children's education (Mean $=-.56$ Logits). However, the item-map showed that challenges to parental involvement were placed on different positions of the interval scale from the biggest challenges located at the bottom side and the smallest challenges located at the upper side based on the item difficulty measures. The parents easily endorsed that their low proficiency in the Chinese language (-0.93 logits) and the complexity of the school subjects ( -0.84 logit) were the biggest challenges to parental involvement. This is supported by the analysis of the parents' demographic profiles, which show that most of the parents have low level of educational qualifications and low level of Chinese language skills. In his study, Snyder-hogan (2010) found that language is a barrier to parental involvement; and there is a significant relationship between family background and parental involvement (Strenze, 2007). Smith (2011) found that communication and language are among the barriers to parental involvement. Parents' educational level is significantly associated with student academic achievement where parents with higher educational level can contribute to children's education by being more involved in their school work at home (Hong \& Ho, 2005; Wang, 2015)

Due to these two biggest challenges (i.e. parents' low proficiency in Chinese language and low educational qualifications), it is not surprising that most of the parents reported that they did not know how to help their children to do well at school (-0.18). Furthermore, the amount of homework that the children have to do made the task more complicated for the parents, (-0.19.logits). The parents admitted that the meetings conducted by the teacher association did not provide them with useful information on how to help and support their children to improve their learning in a more secure and supportive environment at home, (-0.07 logits). The parents could find alternatives to meet these challenges such as hiring tutors. Wang (2015) found that parents' support such as hiring home tutors for their children had significantly influenced students' academic achievement. The school can also contribute by making efforts to communicate and engage parents in a network of professionals to improve their skills in helping their children (Christenson \& Sheridan, 2001; Sheldon, Epstein \& Galindo, 2010).

A percentage of the parents agreed to some extent that the school did not offer them volunteering opportunities to get more involved in children's education at school, (0.25 logits). They did not complain that they did not have enough time to help their children at their schoolwork, (0.34 logits) or the school scheduled activities and conferences at inconvenient times, (0.59 logits). Those parents might have expected more from the school in terms of more organized activities as a way to inspire their children to do better at school. This also indicates that the parents believe that children's education is not only the teachers' responsibility, but 
also the parents'. They are different from the parents who were not involved in their children's learning at home or at school, where they believed that helping students' academic education is the responsibility of teachers/schools, while the parents' responsibility is only for moral education (Smrekar \& Cohen-Vogel, 2001). Therefore, it is important to conduct the activities or meetings for parents at convenient times as it helps more parents to participate and get benefit from the activities. Patrikakou (2008) pointed out that parents could not participate in school activities because meetings were conducted at inconvenient times.

The study results showed that it was difficult for the parents to agree that their children do not want the parents to help them in their study, (1.04 logits), implying that the children are highly motivated to get the help and support from the parents. The children might be influenced by the parents' high aspirations towards their education. Parents' educational aspirations refers to the parents' value of education, their expectations and motivation for their children's education. It is considered as a component of parental involvement in children's education (Snyder-hogan, 2010). Parents' educational aspiration plays a very influential positive role in shaping students' achievement (Fan \& Chen, 2001; Galindo \& Sheldon, 2012; Smith, 2011; Snyder-hogan, 2010; Spera, Wentzel \& Matto, 2009; Wang, 2015). Chen (2010) found that the parents could help and facilitate their children's school life due to their high levels of aspiration towards their children's education.

It is worth stressing that in order to reduce the challenges and increase parental involvement in children's education, families and schools need to play active roles. School outreach programmes have a significant role in increasing parental involvement at school as well as at home (Christenson \& Sheridan, 2001; Sheldon, Epstein \& Galindo, 2010).

\section{CONCLUSION}

The main challenges to parents' involvement relating to their children's education in this study were parents' low proficiency in the Chinese language and the complexity of the school subjects. The study discovered that children were very willing to get assistance from parents due to parents' aspirations towards their education and academic achievement. On the part of parents, they need the school to make them more involved in the school activities and provide them with guidelines or information on how to help and support their children at home. Further research could be conducted using more items and different school grades to generate more insight into these issues. Qualitative research is also recommended to get more in-depth information on the challenges to parental involvement. 


\section{REFERENCES}

Antoine, N. (2012). Teachers and parents' perceptions of barriers to parental involvement in an alternative high school (Doctoral dissertation, Walden University).

Boman, P., \& Curtis, D. (2007). X-ray your data with Rasch. International Education Journal, $8(2), 249-259$.

Bond, T., \& Fox, C. M. (2015). Applying the Rasch Model: fundamental measurement in the human sciences (Third). Routledge: New York.

Bronfenbrenner, U. (1979). The ecology of human development: Experiments by design and nature. Cambridge, MA: Harvard University Press.

Bronstein, P., Ginsburg, G. S., \& Herrera, I. S. (2005). Parental predictors of motivational orientation in early adolescence: a longitudinal study. Journal of Youth and Adolescence, 34(6), 559-575. http://doi.org/10.1007/s10964-005-8946-0

Catsambis, S. (2001). Expanding knowledge of parental involvement in children' s secondary education : connections with high school seniors ' academic success. Social Psychology of Education : An International Journal, 5(2), 149-177.

Chen, J. J.-L. (2005). Relation of academic support from parents, teachers, and peers to Hong Kong adolescents' academic achievement: The mediating role of academic engagement. Genetic, Social, and General Psychology Monographs, 131(2), 77-127.

Chen, Y. (2010). Crossing the frontier to inland China: Family social capital for minority Uighur students in Chinese boarding schools. Chinese Education and Society, 43(1), $46-57$.

Cheng, H.-F., \& Dörnyei, Z. (2007). The use of motivational strategies in language instruction: The case of EFL teaching in taiwan. Innovation in Language Learning and Teaching, 1(1), 153-174. http://doi.org/10.2167/illt048.0

Christenson, S. L., \& Sheridan, S. M. (2001). Schools and Families: Creating Essential Connections for Learning. Guilford Publications.

Creswell, J. W. (2013). Educational Research: Planning, Conducting, and Evaluating Quantitative and Qualitative Research. Sage publications.

Epstein, J. L., \& Karweit, N. (2014). Friends in School: Patterns of Selection and Influence in Secondary Schools.

Epstein, J. L., Sanders, M. G., Simon, B. S., Salinas, K. C., Jansorn, N. R., \& Van Voorhis, F. L. (2002). School, family, and community partnerships: Your handbook for action, 2nd ed.

Epstein, J. L., \& Sheldon, S. B. (2006). Moving forward: Ideas for research on school, family, and community partnerships. SAGE Handbook for Research in Education: Engaging Ideas and Enriching Inquiry, (April), 117-138.

Fan, X., \& Chen, M. (2001). Parental involvement and students academic achievement : A meta-analysis. Educational Psychology Review, 13(1), 1-23. 
Galindo, C., \& Sheldon, S. B. (2012). School and home connections and children's kindergarten achievement gains: The mediating role of family involvement. Early Childhood Research Quarterly, 27(1), 90-103. http://doi.org/10.1016/j.ecresq.2011.05.004

Gao, X. (2006). Strategies used by Chinese parents to support English language learning. RELC Journal, 37(3), 285-298.

Gay, L. R., Mills, G. E., \& Airasian, P. W. (2011). Educational research: Competencies for analysis and applications (11th ed.). Pearson Education Limited.

Graham-Clay, S. (2005). Community with parents: Strategies for teachers. The School Community Journal, 15(1), 117-130.

Green, C. L., Walker, J. M. T., Hoover-Dempsey, K. V, \& Howard M. Sandler. (2007). Parents' motivations for involvement in children's education: An empirical test of a theoretical model of parental involvement. Journal of Educational Psychology, 99(3), 532-544.

Henderson, A. T., \& Mapp, K. L. (2002). A New Wave of Evidence The Impact of School, Family and Community Conections on Study Achievement. National Center for Family and Community Connections with Schools. http://doi.org/10.1016/S0143974X(98)80047-3

Hill, N. E., \& Taylor, L. C. (2004). Parental school involvement and children's academic achievement: Pragmatics and issues. American Psychological Associstion, 13(4), 161164.

Hong, S., \& Ho, H.-Z. (2005). Direct and indirect longitudinal effects of parental involvement on student achievement: Second-Order Latent Growth Modeling across ethnic groups. Journal of Educational Psychology, 97(1), 32-42.

Jeynes, W. H. (2005). A meta-analysis of the relation of parental involvement to urban elementary school student academic achievement. Urban Education, 40(3), 237-269.

Lau, E. Y. H., Li, H., \& Rao, N. (2011). Parental involvement and children's readiness for school in China. Educational Research, 53(1), 95-113.

Linacre, J. M. (2018). Winsteps \& Rasch Measurement (Version 4.1.0) [Computer Software and manual]. Retrieved from www.winsteps.com

Mo, Y. (2008). Parents ' Relationships and involvement: Effects on students 'school engagement and performance. RMLE Online, 31(ISSN 1940-4476).

Patrikakou, E. N. (2008). The Power of Parent Involvement: Evidence, Ideas, and Tools for Student Success. Center on Innovation \& Improvement.

Sheldon, S. B., \& Epstein, J. L. (2005). Involvement counts : Family and community partnerships and mathematics achievement. The Journal of Educational Research, 98(4), 196-206.

Sheldon, S. B., Epstein, J. L., \& Galindo, C. L. (2010). Not just numbers: Creating a Partnership climate to improve Math proficiency in schools. Leadership and Policy in Schools, 9(1), $27-48$. 
Smalls, S. (2010). The Impact of Parental Involvement on Academic Achievement and Behavior of Urban Middle School Students. UMI Dissertation Publishing.

Smith, K. Y. (2011). The Impact of Parental Involvement on Student Achievement.

Smrekar, C., \& Cohen-Vogel, L. (2001). The Voices of Parents: Rethinking the Intersection of Family and School. Peabody Journal of Education, 76(2), 75-100.

Snyder-hogan, L. E. (2010). The Role of Parental Involvement in the Academic Achievement of Latino Youth.

Somers, C. L., Owens, D., \& Piliawsky, M. (2009). A Study of High School Dropout Prevention and At-Risk Ninth Graders' Role Models and Motivations for School Completion. Education, 130(2), 348-356. Retrieved from http://search.ebscohost.com/login.aspx? direct $=$ true $\& \mathrm{db}=$ eric $\& \quad \mathrm{AN}=\mathrm{EJ} 871669 \&$ site=ehost-live\%5Cnhttp://www. projectin novation.biz/education_2006.html

Spera, C., Wentzel, K. R., \& Matto, H. C. (2009). Parental Aspirations for Their Children's Educational Attainment: Relations to Ethnicity, Parental Education, Children's Academic Performance, and Parental Perceptions of School Climate. Ournal of Youth and Adolescence, 38(8), 1140-1152.

Strenze, T. (2007). Intelligence and socioeconomic success: A meta-analytic review of longitudinal research. Intelligence, 35(5), 401-426. http://doi.org/10.1016/ j.intell. 2006.09. 004

Tam, V. C., \& Chan, R. M. (2009). Parental Involvement in Primary Children's Homework in Hong Kong. The School Community Journal, 19(2), 81-100.

Trotman, M. F. (2001). Involving the African American Parent : Recommendations to Increase the Level of Parent Involvement within African American Families Stable. Journal of Negro Education, 70(4), 275-285.

Wang, Y. (2015). A Trend Study of the Influences of Parental Expectation, Parental Involvement, and Self-efficacy on the English Academic Achievement of Chinese Eight Graders. International Education, 44(2), 25.

Wright, B. D., \& Stone, M. H. (1979). Best Test Design. Rasch Measurement. Chicago: Mesa Press. 